\title{
Streams in Forested Headwaters as Reservoirs of Endemicity in Bornean Amphibians
}

\author{
Yong Min Pui and Indraneil Das
}

\begin{abstract}
Tropical forests are known centers of amphibian richness and endemicity. Within these forests, embedded wetlands, particularly streams and other lotic environments, are focal areas of amphibian diversity. Are specific streams or sections of streams relatively more important than others as reservoirs of species richness or endemicity? To address this question, we studied stream-dwelling amphibian assemblages within Gunung Mulu National Park, Sarawak, East Malaysia (Borneo). Six streams were selected, ranging from the headwaters of Sungei Tapin $(1,800 \mathrm{~m}$ asl) to low elevation streams within the Sungei Melinau system, both tributaries of Sungei Tutoh. A $100 \mathrm{~m}$ transect was established at each stream, and standardized visual encounter surveys conducted along each transect at night. A cumulative sampling effort from 35 nights yielded a total of 262 individuals representing 41 amphibian species. Our results indicate greater endemicity in lower order streams (headwaters highest- $80 \%$ ) compared to higher order streams at lower elevations (500 $\mathrm{m}$ asl, $75 \% ;<200 \mathrm{~m}, 42-57 \%$ ). In contrast, species diversity and species richness were significantly greater at larger streams. Species composition at lower elevation streams were more similar to one another, but could be separated into discrete large stream- and small stream- assemblages. These results suggest that species composition of stream-dwelling amphibians is affected by stream elevation or stream width. Our results underline the importance of riparian habitats, especially forested headwaters, in harboring Bornean endemics, a number of which are on the global list of threatened species. These findings support prioritization of stream types and stream segments, especially within forested headwaters, as a regional conservation strategy.
\end{abstract}

\footnotetext{
Y.M. Pui (四) • I. Das

Institute of Biodiversity and Environmental Conservation, Universiti Malaysia Sarawak, 94300 Kota Samarahan, Sarawak, Malaysia

e-mail: pui8783ibec@gmail.com

(c) Springer International Publishing Switzerland 2016

I. Das, A.A. Tuen (eds.), Naturalists, Explorers and Field Scientists in

South-East Asia and Australasia, Topics in Biodiversity and Conservation 15.

DOI 10.1007/978-3-319-26161-4_9
} 